\title{
AÇÕES EDUCATIVAS EM SAÚDE VOLTADAS AO ADOLESCENTE: UM RELATO DE EXPERIÊNCIA
}

\author{
Anna Karina Martins de Oliveira \\ Universidade Federal da Fronteira Sul \\ anna.om@hotmail.com \\ Luana PatriciaValandro \\ Universidade Federal da Fronteira Sul \\ valandro_luana@hotmail.com
}

\author{
Maria Elisabete Calado Ramalho dos Santos \\ Universidade Federal da Fronteira Sul \\ mariaelisa_ramalho@hotmail.com \\ Luciana Alcantara Nogueira \\ Universidade Federal da Fronteira Sul \\ nogueira_lu@hotmail.com
}

\begin{abstract}
Resumo
O presente relato de experiência é o resultado do projeto de extensão, ainda em desenvolvimento, intitulado "Ações educativas voltadas ao adolescente no contexto social e familiar". O projeto está sendo realizado com adolescentes participantes de um programa de ação social, desenvolvido na instituição Fasc, localizada na cidade Chapecó - SC. A metodologia é composta de 5 oficinas que abordam os seguintes temas: sexualidade, gravidez na adolescência, dependência química, violência química e relacionamento familiar. Até o momento foram realizadas 3 oficinas baseadas no método diagnóstico, na qual os adolescentes elaboram perguntas referentes à temática a ser trabalhada no encontro seguinte. Estas servem de base para a composição da oficina que é trabalhada de forma dinâmica, visando atrair a atenção dos jovens. Ao final do projeto, espera-se contribuir para a formação pessoal dos adolescentes em seu contexto familiar, cultural e social. Além disso, têm-se como expectativa a ampliação dos conhecimentos científicos das acadêmicas, favorecendo futuras ações educativas em saúde.

Palavras-chave: Adolescência. Ações educativas. Enfermagem. Saúde.
\end{abstract}

\section{SHARESIN HEALTHEDUCATIONAIMED ATTEEN: AN EXPERIENCE REPORT}

Abstract

This experience report was a result of the extension project entitled "Educational activities aimed at adolescents in social and family context." The project was carried out with adolescent participants of a social action program, developed in SEASC institution, located in Chapecó - SC. The methodology consisted of 5 workshops that address the following themes: sexuality, teenage pregnancy, drug addiction, chemical violence and family relationships. The workshops were based on the diagnostic method in which teenagers elaborated questions concerning the subject to be imaged at the next meeting. These formed the basis for the composition of the workshop that was worked dynamically to attract the attention of young people. The project contributed to the personal development of adolescents in their family, cultural and social context. Furthermore, there was the expansion of scientific knowledge of academic, favoring future educational activities in health

Keywords: Adolescence. Educational activities. Nursing. Health.

\section{ACCIONES EDUCATIVAS EN SALUD DIRECCIONADAS PARA LOS ADOLESCENTES: UN RELATO DE EXPERIENCIA}

\begin{abstract}
Resumen
El presente relato de experiencia fue resultado del proyecto de extensión de título "Acciones educativas direccionadas al adolescente en el contexto social y familiar". El proyecto fue realizado con adolescentes participantes de un programa de acción social desenvuelto en la institución SEASC, localizada en la ciudad de Chapecó - SC. La metodología fue compuesta de cinco talleres de trataron de los siguientes temas: sexualidad, embarazo en la adolescencia, dependencia química, violencia química y relacionamiento familiar. Los talleres fueron basados en método diagnóstico, en el cual los adolescentes elaboran preguntas referentes a la temática a ser trabajada en el encuentro siguiente. Estos servían de base para la composición del taller que fue trabajado de forma dinámica, objetivando atraer la atención de los jóvenes. El proyecto contribuyo para la formación personal de los estudiantes, favoreciendo futuras acciones educativas en salud.

Palabras-clave: Adolescencia. Acciones educativas. Enfermaría. Salud.
\end{abstract}




\section{INTRODUÇÃO}

O período da adolescência, segundo o Ministério da Saúde, ocorre entre os 10 e os 19 anos de idade. Já de acordo com o Art. $2^{\circ}$ do Estatuto da Criança e do Adolescente, o adolescente é o indivíduo com faixa etária entre 12 e 18 anos (BRASIL, 2000).

Nessa fase, acontecem importantes mudanças físicas e psicológicas, influenciadas pela sociedade, cultura e família. A adolescência é um período da vida muito importante para o desenvolvimento dos indivíduos pois, além de sofrerem modificações físicas, estão ampliando e estruturando sua personalidade (OSÓRIO, 1992). De acordo com Ferreira; Alvim;Teixeira;Veloso (2007) o período da adolescência é formado a partir de critérios variados que englobam questões sociais e bio-psicológicas. Tais mudanças resultam em alterações extremas na forma, em sentido biológico e na expressão, em sentido psicológico.

Segundo ERICKSON (1972), é durante a adolescência que o jovem passa por um período de crise, porém de forma construtiva, em que ele está amadurecendo de forma física e mental. Esse momento é de extrema importância para que o adolescente enfrente a fase adulta. Entretanto, esta crise pode se transformar em um desenvolvimento negativo, devido a problemas como a falta de dialogo e compreensão das pessoas que o cercam. Esse problema pode se agravar ainda, considerando a influência que os jovens sofrem dos meios de comunicação e dos grupos de amigos. Devido à dificuldade em tratar de assuntos considerados tabus pela sociedade, muitos adultos se sentem constrangidos para tratar de temas como sexualidade e dependência química com os adolescentes.

Essa problemática se agrava ainda, ao considerar-se que os jovens ingressam precocemente no mercado de trabalho sem nenhum apoio técnico e emocional, deixando de lado seus projetos devida, além de muitas vezes iniciarem sua vida sexual muito cedo. Nesse sentido, a grande gamade informações oferecidas a estes pelos diversos meios, em muitos casos, acabam causando conflitos, resultando no aumento de jovens que ingressando no mundo das drogas e ficam expostos à vários tipos de violência. (FERNANDES, 2009).

Considerando o contexto vivido pelos adolescentes atualmente, é de extrema importância que exista certa atenção a essa fase da vida, uma vez que o jovem da atualidade está mais sujeito aos problemas sociais. Isso exige maior apoio e orientação por parte, não apenas da família, mas também da sociedade como um todo. A área da saúde recebe grande destaque nesse ponto, sendo que é ela a responsável pela prevenção de doenças e a promoção da saúde.

Frente a isso, apresentamos uma proposta de extensão intitulada "Ações educativas voltadas ao adolescente no contexto social e familiar", que foi realizada em uma instituição 
Ações educativas em saúde voltadas ao adolescente: um relato de experiência

(Secretaria de Assistência Social de Chapecó - SEASC) que desenvolve ações socioeducativas, com o objetivo de trabalhar temáticas do cotidiano dos adolescentes por meio de oficinas em que os participantes expressavam seus anseios e dúvidas a partir dos temas expostos.

O presente projeto teve como objetivo principal desenvolver ações educativas voltadas aos adolescentes participantes de um programa socioeducativo realizado no bairro Passo dos Fortes na cidade de Chapecó/SC, considerando o contexto social e familiar. Além disso, por meio das oficinas que tratam das temáticas sexualidade, gravidez na adolescência, dependência química, violência e relacionamento familiar, objetivávamos promover o diálogo entre os adolescentes, permitindo que estes expressassem suas dúvidas e compartilhassem suas experiências. Por meio da interação entre a universidade e a comunidade objetivava-se também, agregar o conhecimento trazido pelos adolescentes ao conhecimento cientifico adquirido pelas acadêmicas ao longo da graduação.

A partir disto, o presente relato de experiência tem como objetivo, divulgar a experiência obtida pelas acadêmicas do curso de enfermagem da Universidade Federal da Fronteira Sul na execução de um projeto de extensão universitária com adolescentes participantes do programa Arte Jovem desenvolvido pela SEASC de Chapecó -SC.

\section{CARACTERIZAÇÃO DO LOCAL DE DESENVOLVIMENTO DO PROJETO}

A SEASCé uma organização vinculada à Prefeitura Municipal de Chapecó - SC, que auxilia crianças, adolescentes, adultos e idosos em geral, por meio de programas socioeducativos e assistenciais, visando a melhoria da qualidade de vida desses indivíduos. É dividida em setores específicos de atendimento à população. Um desses setores de atendimento é o Programa Arte Jovem que atende adolescentes de 14 a 16 anos, nos turnos matutino e vespertino, vindos a partir de encaminhamento do Centro de Referencia a Assistência Social - CRAS. Nesse local, os jovens desenvolvem oficinas de serigrafia, cartonagem e outras atividades com material reciclável, além de aulas de informática. Os produtos desenvolvidos durante o ano no Programa Arte Jovem, são vendidos e o valor arrecadado é destinado aos próprios adolescentes que, ao final do ano podem realizar uma viagem ou outra atividade definida por eles. 


\section{MATERIAL E MÉTODOS}

Embasado nos objetivos do projeto buscou-se por uma metodologia que permitisse que as temáticas fossem trabalhadas de forma dinâmica e de fácil compreensão, atraindo mais a atenção dos adolescentes.

Para que os adolescentes se sentissem mais confortáveis, foi desenvolvido um sistema diagnóstico, que consiste em uma caixa na qual os jovens depositavam suas dúvidas a respeito da temática que será tratada no encontro seguinte. Este sistema possibilitou às acadêmicas elaborar um encontro mais interessante para as turmas, já que este se baseia em seus questionamentos.

Ao final de cada encontro foi realizado uma avaliação com o objetivo de aprimorar as oficinas seguintes baseado na opinião dos participantes.

Após a coleta das perguntas dos adolescentes e das avaliações realizadas por estes, as acadêmicas pesquisam a respeito da temática da oficina em artigos científicos e outros materiais acadêmicos.

\section{O DESENVOLVIMENTO DO PROJETO}

O projeto foi realizado com duas turmas, sendo uma no período matutino e outra no vespertino. A quantidade de participantes variou, tendo aproximadamente 13 adolescentes no período matutino e 20 no período vespertino, totalizando 33 adolescentes atendidos pelo projeto. Originalmente o projeto foi pensado em 5 oficinas, entretanto optou-se por realizar uma oficina extra de apresentação do projeto com ambas as turmas, para que as acadêmicas pudessem apresentar a proposta e conhecer as turmas com quem trabalhariam ao longo do ano.

No encontro de apresentação, realizado nos dias 02 (no turno matutino) e 13 (no turno vespertino) do mês de abril, foi levado aos adolescentes uma apresentação de slides contendo os objetivos do projeto e as temáticas que seriam trabalhadas ao longo do ano. Além disso, foi realizada uma dinâmica, na qual cada participante recebia uma parte de uma frase que deveria ser unida a outras duas partes. As frases se referiam a temas como união, trabalho em grupo, amizade e tomada de decisão. Ao unirem as três partes, o grupo debatia sobre a frase e expressavam suas opiniões a respeito desta, além de realizarem uma pequena apresentação pessoal. Ao final do encontro, as acadêmicas expressaram suas expectativas de trabalho ao longo do ano baseadas nos temas tratados na dinâmica. 
A primeira oficina, realizada nos dias 30 de abril (no período matutino) e 04 de maio (no período vespertino) foi debatido o tema sexualidade enfocando as dúvidas encontradas no método diagnóstico, realizado no primeiro encontro. Para trabalhar a temática, foi preparadauma apresentação de slides tratando dos seguintes assuntos: conceito de sexualidade, puberdade, atração sexual, virgindade e doenças sexualmente transmissíveis (DST’s). Nesse encontro, a temática foi apenas debatida, sem a realização de nenhuma dinâmica, o que permitiu as acadêmicas perceberem que os adolescentes encontravam dificuldades em expressar suas opiniões a respeito da temática e que estes possuíam maior interesse por atividades dinâmicas.

$\mathrm{Na}$ segunda oficina, realizada nos dias 28 de maio (no turno matutino) e 01 de junho (no período vespertino), trabalhou-se a temática gravidez na adolescência, procurando responder as perguntas elaboradas pelos jovens no diagnóstico. Nesta oficina, foram debatidos os seguintes temas: como ocorre a gravidez, período fértil, menstruação, como identificar a gravidez, métodos de confirmação da gravidez, pré-natal e cuidados durante a gravidez, sexualidade na gravidez e métodos contraceptivos (preservativo feminino e masculino e pílula anticoncepcional). $\mathrm{Na}$ decisão dos métodos contraceptivos que seriam trabalhados, foi levado em consideração a condição social e econômica dos participantes, de forma que estes tivessem facilidade de acesso aos mesmos.

Ainda na segunda oficina, foi realizada uma dinâmica com balões, na qual os adolescentes puderam vivenciar o compromisso do cuidado com as crianças. A dinâmica consistia em formar grupos de 1, 2 e 3 componentes e distribuir um balão a cada equipe. Após encher o balão, foi solicitado que cada grupo desenhasse o rosto de um bebê. Os adolescentes deveriam cuidar deste ao longo da apresentação e ao ouvirem o choro do bebê, trazido pelas acadêmicas, deveriam tentar acalmá-lo. Além disso, ao longo da oficina, os adolescentes deviam realizar atividades enquanto seguravam o bebê. As atividades incluíam montar um quebra-cabeça com a palavra gravidez e organizar três peças de roupa enquanto o bebê chorava. Ao final da oficina, as acadêmicas debateram com os jovens as dificuldades encontradas no cuidado de uma criança.

A terceira oficina, realizada no dia 31 de agosto (no turno matutino e vespertino), foi debatido o tema dependência química. $\mathrm{Na}$ oficina foram trabalhados os seguintes temas: conceito de dependência química, dependência química como doença física e psicológica, definição de droga, drogas lícitas e ilícitas, álcool, tabaco, maconha, cocaína, crack, overdose e tratamento. Para discussão dos temas, foi realizada uma dinâmica, na qual os adolescentes foram divididos em dois grupos e receberam duas placas, uma contendo a palavra "certo" e outra a palavra "errado". Durante a oficina, foram apresentadas aos grupos 10 afirmativas referentes ao assunto e estes 
deveriam julgar se consideravam certo ou errado. Após a correção de cada afirmativa, o assunto era debatido e as acadêmicas traziam aos jovens a visão científica do tema.

Na quarta oficina, desenvolvida nos dias 05 (no período da manhã) e 11(no período da tarde) de outubro, foi trabalhado o tema violência. Nesse encontro as acadêmicas buscaram trabalhar de forma a realizar uma roda de conversa com os jovens. A dinâmica proposta consistia em distribuir aos grupos de adolescentes, já previamente divididos, pequenos textos que tratavam de diferentes tipos de violência comuns na atualidade. Dessa forma, os mesmos deveriam realizar uma pequena discussão entre si sobre o seu respectivo tema e posteriormente explica-lo ao grande grupo. Isso possibilitou que os jovens expusessem as suas experiências pessoais e suas opiniões sobre os temas.

Por fim, na quinta oficina, realizada no dia 27 de novembro, nos períodos da manhã e da tarde, foi trabalhado com o tema relacionamento familiar. Nesse encontro, buscou-se tratar de assuntos como conceito de família, tipos de família encontrados nos dias atuais, planejamento familiar e diálogo. Para isso, foi utilizada a dinâmica do desenho. Primeiramente, antes que a oficina fosse iniciada, os jovens deveriam retratar em forma de desenho a imagem de família que cada um possuía. Posteriormente a isso, após os debates sobre o tema, os adolescentes puderam comparar a sua ideia final de família, com o conceito inicial elaborado por eles antes mesmo das discussões. Isso possibilitou que os jovens passassem a perceber o grupo familiar de uma forma diferente daquela tradicional, composta apenas por pai, mãe e filho.

Baseando-se em uma das metas da Universidade Federal da Fronteira Sul, que preza o ensino, pesquisa e extensão como requisito para existência de um ensino crítico, investigativo e inovador, o presente projeto apresentou-se positivo, pois além de oferecer debates que permitem aos adolescentes expor suas experiências e conhecimentos, ainda agregou as acadêmicas novos saberes científicos e populares.

\section{CONSIDERAÇÕES FINAIS}

O período da adolescência é caracterizado por novas descobertas e tomadas de decisão essenciais para a formação da personalidade do indivíduo, além de ser uma etapa composta de modificações físicas e comportamentais. Neste contexto, ressalta-se a importância das ações voltadas ao adolescente, contribuindo para o desenvolvimento do indivíduo tanto no âmbito social, como familiar. 
Ações educativas em saúde voltadas ao adolescente: um relato de experiência

Após a realização do presente projeto, pode-se perceber que assuntos que muitas vezes são tidos como já entendidos pelos adolescentes, ainda continuam despertando dúvidas nos mesmos. Dessa forma, os temas propostos foram recebidos pelos jovens de forma muito positiva, já que estavam voltados ao seu cotidiano. A forma que os encontros foram conduzidos, também contribuíram para o entendimento e para a interação dos jovens com os assuntos, já que buscou-se estimular o interesse dos mesmos através das dinâmicas e das informações de fácil compreensão.

Ao final do presente projeto de extensão, concluiu-se que o mesmo contribuiu de grande forma para desenvolver um trabalho social com metas voltadas para as necessidades da comunidade, de forma coerente com a formação dos indivíduos, proporcionando a melhoria na formação do cidadão.

\section{REFERÊNCIAS}

BRASIL, Ministério da Saúde. Secretaria de Políticas de Saúde. Área de Saúde do Adolescente e do Jovem. Cadernos, Juventude e desenvolvimento, v.1. Brasília, DF, agosto, 1999.

BRASIL. Ministério da Saúde. Estatuto da Criança e do Adolescente/ Ministério da Saúde. Editora do Ministério da Saúde; Brasília: 2008, 3ª edição, 96 p.

OSORIO, L. C. Adolescente hoje. Porto Alegre: Artes Médicas, 1992. 103 p.

ERIKSON, E. H. (1972). Identidade, juventude e crise. Rio de Janeiro: Zahar.

FERREIRA, M.A.; Alvim, N.A.T.; Teixeira, M.L.O.; Veloso, R.C. Saberes de adolescentes: estilo de vida e cuidado a saúde. Texto Contexto Enfermagem. Florianópolis: 2007, abriljunho; 16 (2): $217-24$.

FERNANDES, Elizabete Cordeiro. Políticas de Atenção Integral à Saúde dos Adolescentes eJovens - PROSAD. Disponível em: <http://www.artigonal.com/ensino-superiorartigos/politicade atencao-integral-a-saude-dos-adolescentes-e-jovens-prosad-1054873.html > . Acesso em 14 de novembro de 2012. 